\title{
PAPERS
}

\section{A Collaborative Future within Atla}

\author{
How Theological Libraries Must Work \\ Together in the Digital Age
}

Richard Manly Adams, Jr., Pitts Theology Library at Candler School of Theology

\begin{abstract}
In a post-pandemic, digital world, collaboration between libraries and librarians is more important than ever. This essay argues that Atla members should look to the Association itself as a way of working together. I proceed first by outlining the great history of the Association as a collaborative space for its members, highlighting three past successes. I then apply the four causes of success from these past projects to the challenges we face in a digital age that has been disrupted by the pandemic. I explore how Atla libraries can collaborate on collection development, digitization, and information literacy instruction, and what the opportunities and limits of working together may be.
\end{abstract}

By now, Atla members are likely becoming accustomed to the name change of our organization. In 2019, the Atla board approved a new brand system and changed the name of the organization from the American Theological Library Association, its name when founded in 1946, to Atla (Bartholomew 2019). Regardless of what one may think about the name, the logo, or the new branding, I find certain logic to the name change. The former name, the American Theological Library Association, is limiting and does not reflect the membership and the work of the organization. "American" is not reflective of membership or the "diverse global community" the organization seeks to foster. "Theological" is a remnant of the past, when original 
members supported Christian schools of theology, and now members support much broader domains of learning. Even the term "library" is problematic, since membership includes museums, archives, and other information institutions.

I want to pause for a minute this afternoon and think about the final "A" in the old name: "Association." What do we mean by referring to ourselves as "an association," and is that designation one that we want to continue, even in a newly branded world? How and for what purpose do we, the membership of Atla, associate? My argument in this essay is quite simple, perhaps even obvious: This "association" is more important than ever in this digital and postpandemic world. For us to survive and thrive as individual libraries and librarians, we must work together. Fortunately, our shared association, Atla, has a long history of successful collaboration, of libraries and librarians coming together and uniting their unique skills, collections, and ideas, to tackle problems facing all libraries. And, therefore, my argument might be understood simply as a call to reclaim our roots, to double down on our collaborative nature.

My approach to explore this "association" in this essay falls into two sections, one descriptive and one prescriptive. I spend some time looking at highlights in the association's past, with hopes to draw lessons from those who came before. Then I turn to offer some thoughts on the challenges now facing our libraries with suggestions for how members can work together to achieve the same type of success. I frame our conversation around three broad areas of librarianship that have been and will continue to present some of our greatest challenges as individual libraries and greatest opportunities as an association: information literacy, preservation and access, and collection development.

In telling the history of our organization from its inception in 1946 to 1996, Elmer and Betty O’Brien note, “Within two years of its founding, seventy-six percent of seminary libraries affiliated with the AATS had joined, and a united attack on theological library problems had begun" (O’Brien 1996, 8). I like that phrase, "a united attack on theological library problems.” Such problems are very different now than they were in 1946 or even 1996. But given that we are in the midst of our 75th anniversary as an association, I would like to spend the rest of our time today looking at that development of our challenges and to propose a few ways we all can launch anew our "united attack on theological library problems." 


\section{“ASSOCIATION" THROUGHOUT OUR HISTORY}

Atla members are blessed to have ready access to the association's history through several published volumes. I encourage all members to mine the treasures that are the two major publications on Atla's history, both available as open-access e-books via Atla's website (Graham 1996 and McMahon 2006). In these volumes, as well as throughout the proceedings of the annual Atla conference, members can learn about the origins of this term "association" and its historical meaning for member libraries and librarians.

The original constitution of the Association states a number of purposes for this first association: "The purpose of the Association shall be to bring its members into closer working relations with each other; ... to study the distinctive problems of theological seminary libraries, to increase the professional competence of the membership, and to improve the quality of library service to theological education" (Proposed Constitution 1947, 75). As the constitution states, much of the early function of the Association was about professionalization. This work of developing a profession of theological librarianship was a response to earlier studies that had identified the need for a systematic approach to librarianship supporting theological education. For example, in 1934, The Institute of Social and Religious Research had issued a three-volume work entitled The Education of American Ministers, the third volume of which, written by Mark May, focuses on the institutions that train ministers (May 1934). In his essay on theological libraries, May offered six recommendations, all focused on credentialing of staff and the inadequacy of budgets. Early on, the work of the Association was to set the standards and to create language and practices that would define this emerging subspeciality: the theological library.

What is so remarkable about the early history of Atla, though, is members acting upon the charge "to study the distinctive problems of theological seminary libraries." From the beginning, the membership did not merely study these distinctive problems, but they got to the work of solving them. The Association, as early as its second proceedings, shows signs of creating a collaborative workspace to solve problems that no single member institution could solve on its own. The Association became a meeting ground for libraries to work together to solve these problems that they were all experiencing.

Reports from the history of Atla are filled with tales of collaboration between libraries on projects that mutually benefit the member- 
ship. For this essay, I spend some time highlighting three, in three distinctive areas of librarianship, with hopes that these past successes can teach present members something about collaboration in our current age, as they face new challenges in these same three areas.

\section{PERIODICAL INDEXING}

A first example involves information literacy. Perhaps the earliest example of the Association's collaborative attack on problems was a solution to challenges librarians had been facing with research and discoverability: the creation of the index to religious periodical literature, the precursor to the well-known Atla Religion Database. This history has been told with great clarity in the 1974 essay by G. Fay Dickerson and John A. Pelz (Dickerson and Pelz 2006). The index was a collaborative solution to a need identified as early as 1937 in a survey conducted by the Religious Books Round Table of ALA. In that survey, 79 librarians agreed that better indexing of religious materials was essential for their work of helping students and researchers absorb the growing body of literature in theology. The late nineteenth to early twentieth century was the true adolescence period of theological research, particularly in North America, and scholarly output had simply become overwhelming for students, pastors, and faculty. Despite the clamoring of ALA's membership, there was no organization to take on this challenge, and as Dickerson and Peltz note, "a full decade passed and this need was still unmet" (Dickerson and Pelz 2006, 298). Ten years later, the new ATLA organization confirmed the need through their own survey. The Religious Periodical Indexing committee was appointed at the first ATLA annual meeting, and the first volume of the index was completed within 5 years of the organization's founding. This work was the product of collaborative research across twenty different libraries (more than a quarter of the membership of the new organization), and it was completed with no external funding, which only came later. Since then, the index has continued to grow to keep pace with the output of scholarship, and leadership, participation, and hosting of the project has migrated across member institutions. In the very first year of the Association's history, members find a wonderful example of what I argue is a developing trend: members identify a problem that no single institution can solve on its own, and through collaborative effort, the membership solves it together. 
This initial collaborative spirit is evident in another challenge the membership took on soon afterwards: concerns about access and preservation, which were met through the ATLA microfilming project. The history of this project has also been well documented, in Myron B. Chace's article in the fifty-year anniversary volume (Chace 1996). Collaborative microfilming grew out of two great concerns shared by member libraries: how libraries might access expensive materials in a growing field and how the publication history of theology might be preserved long-term. For many libraries, microfilming was initially viewed as a way for institutions to gain "on-demand" access to rare and expensive publications. Increasingly, though, the project was also viewed as a way of preserving the legacy of theological publications, particularly those nineteenth- and early twentiethcentury publications often printed on brittle paper. From the 1950s through the 1990s, members collaborated to film over 1,800 periodicals and more than 30,000 monographs, securing multiple rounds of funding, assessing and switching between technologies, and incorporating feedback from dozens of institutions. Key to the success of this program was the shared responsibility of selecting items for filming, so that the resulting repository reflected the diverse output of theology and met the diverse needs of researchers and libraries. As the coordinator Raymond Morris reported, "Every member of the Association is in some degree responsible for determining what types of material are required by our Association” (Chace 1996, 52). Chace summarizes the effort as follows: "In establishing the first, large-scale (for the time) ATLA microfilming project, Morris-consistent with Association values-emphasized its cooperative, memberdirected character" (Chace 1996, 49).

The results of this member-directed project are remarkable. Most theological librarians have been the beneficiaries of this work, either in their own research or in their work supporting the research of patrons. Thanks to this collaborative effort, an entire generation of theological scholarship is preserved and accessible.

A third successful collaboration was one focused on collection development. One of the consistent problems identified at early ATLA meetings was inadequate acquisition budgets. This was another problem that our association was successful at attacking collaboratively. Consider these stats, reported by Paul Stuehrenberg about library acquisition budgets in the 1950s and 1960s: "The average expenditure that year [1956/57] was $\$ 5,960$. For 1961/62, the first 
year of the Program, the expenditures on books and periodicals of the twelve top participating libraries averaged $\$ 16,857$; by $1964 / 65$ that average had increased to $\$ 39,710$ " (Stuehrenberg 1996, 61).

This "program" to which Stuehrenberg refers is the ATLA Library Development Program, a collaboration between ATLA and the Sealantic Fund, an organization that had already financially supported ATLA's work. Spearheaded by Raymond Morris of Yale Divinity School Library, the program was designed to provide matching funds, up to $\$ 2,000$ per year, to seminaries that grew their library acquisitions budget. The response was overwhelming, and the full $\$ 875,000$ grant, planned for five years, was spent in just three, though it was eventually funded for an additional two years. The result of this infusion of acquisition funds was a growth in acquisitions, but growth far beyond the amount donated by Sealantic. Indeed, the impact of this grant went far beyond the influx of acquisition funds. Such an innovative program had the effect of opening up seminary administrators to the idea of building a strong library as a core part of the educational mission of schools. As Stuehrenberg reports, "During that fiveyear period the level of institutional support for theological libraries was increased dramatically; irreversibly so, as it proved to be.... Not only had the libraries been enabled to purchase several thousand volumes they otherwise would have been unable to acquire, seminaries dramatically increased their continuing commitments to their libraries, both in terms of acquisitions budgets and in overall expenditures for library support. There was no going back" (Stuehrenberg 1996, 64).

Offering careful reflection on this project, one of the most successful in our Association's history, Stuehrenberg offers four helpful lessons for ATLA members:

1) Involve as Many Members as Possible-Close to 100\% of ATLA member libraries participated in the program;

2) Leverage Existing Resources-The program used the grant to raise local money;

3) Allow Decentralized Decision-Making-Member libraries decided what they needed to collect in their local contexts;

4) Know When Enough is Enough-Morris cut the program off after five years so libraries would not become dependent upon it for acquisitions (Stuehrenberg 1996, 65). 
These three collaborative solutions to challenging problems of information literacy, preservation and access, and collection development represent the hallmark of our Association. While Atla continues to provide a forum for defining and advocating for best practices, and while the professionalization function of Atla remains important, it is this coming together, the marshalling of talents and human power across institutions to solve problems, that is the remarkable legacy of the Association. The heart of this organization has not only been the formulation of best practices around credentialing, budgeting, cataloging, etc. Members have also, from the beginning, identified problems the solution to which lies beyond the capacity of a single library, and they have partnered together to harness the capacity and talent of members to provide solutions that benefit all. The martial language of the O'Briens, quoted earlier is apt: Atla members have attacked the theological library problems; and indeed collections, discovery tools, and joint ventures speak to these successes. The Association has been most successful in joint ventures when working with a diverse group of collaborators and being strategic in the form of that collaboration. This is key, particularly in the present context in which there is a lot of talk about collaboration. We know we are called as librarians to collaborate. The question is, "Why and how are we working together?”

To drive this focus on strategy, I return to these four lessons that Paul Stuehrenberg identified when reporting on the ATLA Library Development program. I argue these four serve as a key to developing strategic collaboration for Atla moving forward:

1) Involve as Many Members as Possible

2) Leverage Existing Resources

3) Allow Decentralized Decision-Making

4) Know When Enough is Enough

Each of these four could be applied to the periodical index work or the microfilming project as easily as Stuehrenberg applied them to the library development program. And so, as I turn now to look at future opportunities for collaboration in these same areas, I use those four as a heuristic device to outline how, in the face of real challenges to our work, we can best collaborate to succeed together. 


\section{WHAT HAS CHANGED?}

Given this past as our prelude, I turn now to argue for continuing Atla's tradition of a united attack on theological library problems. To do so, of course, I have to start by asking, "What are the theological library problems that we need to attack?” There are plenty to choose from, of course. As we turn to look at the future, there are two dominant disruptors that influence any challenge against which we will mount a "united attack." Both disruptors may seem obvious, but I believe both need thoughtful and critical reflection.

The first disruption is the proliferation of digital technologies and the digital mode of work in libraries. The rise of the digital affects all aspects of library work, from collection development, with the growing demand and availability of electronic resources, to library instruction, with growth of evergreen content like LibGuides and virtual classrooms, to library outreach, with digital exhibitions and virtual events, to entire new areas of librarianship, such as digitization and digital scholarship. In addition, patrons are increasingly more digital natives than digital immigrants, and thus they have certain expectations about access. Digital tools, texts, and methods provide opportunities for librarians to work together, but they also complexify the work, demand new skills in librarians' toolboxes, and threaten to pull all librarians away from the core mission for which they were trained.

The second disruption is more immediate: the pandemic all have endured and continue to endure. All likely recognize that this past year of pandemic is a point of inflection for all aspects of our society, certainly higher education, and most certainly the work of libraries. As librarians have had to adapt just about every part of the patron service model, the question of what to keep from pandemic times and what to get rid of is one I fear many are making too quickly. That is, many are rushing out of the pandemic just as quickly as they were forced to rush in.

I find it most helpful to think about the pandemic as a catalyst for change that was already underway. The long tail effects of the pandemic are multiple. Budgets, of course, which were already tight, will suffer from the pandemic. This is not only a short-term crisis, but I imagine few of us are optimistic about those funds ever returning. The change in instruction models, curricula, and modes of degree delivery are also accelerated due to the pandemic. What seminary is not considering an online or hybrid MDiv, and thus what library 
is not being forced to consider how to deliver high-quality resources to patrons spread around the country or around the world?

In many ways, the pandemic and the digital age present the perfect storm of disruption heading our way, and no aspect of our work will be untouched by them. In what follows, therefore, I take the three areas considered in the discussion of Atla's history-collection development, access and preservation, and discoverability/ info literacy-and I look at problems librarians are sure to face in the coming years, particularly as the impacts of the digital and the pandemic become clearer.

\section{COLLECTION DEVELOPMENT}

I begin where Paul F. Stuehrenberg was working: how librarians build collections in this digital age. The persistent challenge of building collections is exacerbated by both the digital and the pandemic. Building a library collection has always been a balance between the ideals of preservation and access, on the one hand, and the logistical limits of local budgets and capacity, on the other. The narrative of academic libraries in the twentieth century presents a struggle between these poles. Complaining about limited budgets is nothing new for modern librarians, of course. With limited budgets, libraries are forced to choose between collecting wide and collecting deeply, or between acting as preservation repositories or points of access. The understandable tendency in such situations is to prioritize current access and curricular need over historical preservation. That is, in the face of tight budgets, we build our library for the researcher in front of us, not the researcher fifty years from now. The result can be highly idiosyncratic collections. As a 2001 report from CLIR notes, "Research libraries, no matter how large, collect only a small portion of all the information created and disseminated at any given time. In the nineteenth and early twentieth centuries, most academic libraries were shaped directly by the research needs of their faculties. This resulted in some very rich veins of bibliographical ore, but it also generally produced holdings that were deep, but not broad, in coverage” (Nichols and Smith 2001, 83). Thankfully, libraries have in place systems to account for this challenge. Interlibrary loan, of course, is the shining example, affording libraries access to collections around the world. But the pandemic and the rise in digital access demand exacerbates what was already a troubling trend in collection devel- 
opment. Sara Morris and Jenny Presnell start a particularly important article on collection development, written pre-pandemic by the way, with the line, "The new realities of academic libraries are limited space, complicated access models, shrinking budgets with competing interests in print as well as electronic, and increasing demands by users for digital and instantaneous access" (Morris and Presnell 2019, 379).

It is this last point raised by Morris and Presnell that has me particularly concerned in the present context. Not only does the pandemic have the likely effect of squeezing collection budgets even more, if such a thing were possible, but the push for emergency digital access, accelerated by the inertia of remote learning and distance education, has forced many libraries into investing in electronic resources, often at the expense of purchasing fewer print collections. As more users demand e-books, and as increased demand to support remote learning presses us toward e-books, tried and true solutions like ILL may not be a sustainable. As Morris and Presnell note, "As we shift to more e-books, the magnitude of this problem will only increase. Some consortial e-book models do provide sharing among the members, but nonmembers cannot borrow the title. Librarians must remember that what you do not own, you cannot control" (Morris and Presnell 2019, 381).

Demands on tighter budgets and a growing patron base spread around the country also places pressure on libraries to save space and processing costs by weeding physical collections, focusing capacity on materials that serve the present patron or redeploying library shelf space as offices or classrooms. Few libraries are afforded the luxury of collecting for posterity. The 1970s reference book does not present the current state of research, so the librarian's tendency, under tightened constraints, is to free up shelf space and get rid of it. I foresee this collection development challenge as one of the defining ones for our coming age. So, how is Atla to collaborate to attack this problem?

It would be folly to propose a single solution that is going to solve these challenges. I do, however, find that running collection development through Stuehrenberg's four points helps us formulate a strategy.

First, in collection development, we should "involve as many members as possible.” With collection development, collaboration is going to be key, as we are increasingly reliant on one another for 
shared collections. Not only should we be sharing collection development policies, but we should also be considering the sharing of resources when we make decisions about print versus electronic purchases. In addition, when weeding collections, we should recognize that most theology libraries are weeding the same theology collections, and thus there is a preservation danger, particularly if we start to make weeding decisions based solely on recent use. One might imagine Methodist libraries ending subscriptions to Baptist print periodicals without a conversation with Baptist institutions about whether someone will be able to provide access to the title in question. We must broaden our conversations about our collections and shift our purview away from considering ourselves as isolated repositories, looking only at what we can provide to our patrons, and consider ourselves nodes of access in conversation with our Atla partners to know who is collecting what and how access can be shared.

Second, we must "leverage existing resources." This conversation about collaboration on collection development prompts an emphasis on the local collection. If we can move into a collaborative space on collection development, then those idiosyncratic collecting habits actually work to librarians' advantage. Collection development should proceed at the local library level with some sense of the focus and strength of our local collections and that of other libraries. This is certainly true of special collections, where libraries have a history of narrowly focusing our collections. As budgets are squeezed and collection practices change in general, though, we need to understand who we are and what we have traditionally done well, and to share that with other institutions for the benefit of all.

Third, librarians should "allow decentralized decision-making." Collaboration does not mean that librarians give up the local for the sake of the whole. Instead, we have to recognize that our interests are local, and we have to support our patrons, but also recognize that we can do this collaboratively. In my own context at Emory University, for example, there have been significant changes to the curriculum, as the mode of theological instruction and the relative value of different areas of study are changing. New programs, such as an emphasis on Muslim/Christian dialog, force my colleague Caitlin Soma, our acquisitions librarian, to play catch up to build a collection to support new curricular interests. I argue that libraries must be nimble enough to collect in new areas, but we must also be aware 
of historical collections that may support us in this effort, and we need to be able to rely on our partner organizations to help us when budgets don't support new collections.

Finally, following Stuehrenberg, in collection development we must "know when enough is enough." This to me is the important limit in collaborative approaches to collection development. We cannot allow libraries to become too dependent on consortial lending. There are core resources that your patrons need, such as reference collections. Individual libraries should focus on those. This is one area, I would argue, where electronic resources may be most valuable in providing quick and easy reference materials to my patrons. While I work with other libraries to understand the landscape of resources that may be available, I still need to develop my ability to serve my local patrons efficiently.

Crises present opportunities, and I believe the effects of the digital age magnified by the pandemic presents an incredible opportunity for us to move away from thinking of ourselves as silos of resources for our local patrons to nodes of access for a broad set of patrons. This will only work, though, if we carefully collaborate with one another.

\section{ACCESS AND PRESERVATION}

From collection development, I now turn to consider access and preservation in a post-pandemic digital age. Just as the Atla microfilming project helped solve a crisis of access and preservation for libraries in the 1950s and 1960s, so a collaborative approach to digitization can help us all. Technology has changed away from the microform, of course, but our strategy should not change; we must work together to grow access to the incredible resources of our libraries.

The challenge of the post-pandemic digital age is the growing expectation of digital access and the increasing practice of curating research interest based on access. The first question many patrons ask, particularly with regard to special collections, is whether all materials have been digitized. During the pandemic, this demand for digital access has clearly increased, and the restrictions brought by the pandemic have revealed a sharp divide between those institutions that have digital collections and those who do not, as research access to special collections was removed with little or no warning. 
The expectation of digital access is not going to go away. Travel budgets for scholars will be smaller, and habits have shifted toward an assumption of digital access, and so the old model of a scholar diving into a physical archive will be less and less prevalent. The onus now falls to the library and its digitization team to provide ready access to collections, complete with quality metadata to aid in discovery. Otherwise, collections will have less and less impact each year as the digital becomes the norm and the scholar's expectation. The challenge for librarians is not only digitizing materials, but exposing that metadata for discovery, the challenge of advertising digitally what we have available.

To date, digitization efforts, like collection development, have been too much of an individual library effort. Just as libraries have historically raced to build up the largest repository of books, accessible to local patrons, so libraries have raced to build up the largest repository of digital assets, discoverable by those who know the proper URLs and know the idiosyncrasies of particular discovery layers. New technologies and the immediacy of the pandemic offer the chance to change that, to rethink digitization practices. So, let us consider what digitization might look like in the future, using Stuehrenberg's model.

First, digitization practices should "involve as many members as possible." The most immediate barrier to entry into the space of digitization is funding. Libraries need funding not only to digitize their collections, but to improve metadata, build repositories, and increase discoverability. This barrier is most successfully overcome by external funding. But in an increasingly competitive funding environment, cross-institutional collaboration is the most successful way forward. As CLIR noted in 2018, "Increasingly, inter-institutional collaboration seems to be the way funders want their constituencies to do their work.... We believe that when collecting institutions jointly align digitization priorities and approaches, they can provide broader access and more consistent service to their communities of users, maximizing the potential impact of sharing their collections while minimizing duplication of effort" (Banks and Williford 2018). So, I call for Atla members to work together and write grant proposals that bring collections together in the digital space. Atla has a terrific history of coordinating grant proposals, such as the 2018 funded project "Digitizing the Records of Philadelphia's Historic Congregations," which resulted in thousands of church records from 
Philadelphia being preserved, digitized, and ingested into the Atla digital library. All members should seek natural partners across the Association that would strengthen collections, and the membership should approach external funding opportunities less as competitors and more as partners to create more competitive proposals.

This collaboration should cut across institutions, joining large and small libraries. An institution's size may say something about its internal resources to pay for digitization, but it says nothing about the import of its collections. I encourage large institutions to look to smaller ones as partners, and I encourage smaller institutions to raise awareness about their collections so that they can participate in grant projects, often led by larger ones. As Latoya Devezin of CLIR notes, "As funding resources become scarcer, the ability to work cross-institutionally between small and large organizations remains imperative" (Devezin 2017).

Second, in digitization efforts, we should "leverage existing resources.” Beyond working together to secure funding to grow digital collections, libraries should also recognize that there is in place the infrastructure to grow discoverability of existing digital collections. This is yet another place where the previous work of Atla really benefits all of its members. The Atla Digital Library, which I hope all members are aware of, is an incredible resource that all should take advantage of. This repository allows members to combine digital assets into a single presentation of "theology online," giving researchers greater probability of finding our digital collections. In the future, Atla may also help those institutions without the technical infrastructure to present digital assets through the repository. Even those who are already hosting their own digital content should contact Atla about having metadata harvested. This is a great opportunity to direct patrons to all of the incredible theology resources available online.

In addition to collaborating for funding and infrastructure, libraries must "allow decentralized decision-making” with regard to digitization. Even as libraries move to centralize external funding efforts and potentially discovery layers, they should not lose the power of local knowledge of collections and patrons. Each library knows best what is in its collections, what presents a preservation risk, and what patrons are demanding in digital access. We should work to keep those decisions at the local level, but we should advertise those 
decisions so that we have increased awareness of what is available digitally and what needs digitization.

Finally, libraries should "know when enough is enough" with collaborative efforts at digitization. As with anything, the danger of centralization is overdependence on the consortium and the loss of local knowledge. As Raymond Morris smartly cut off the Library Development Program to ensure that local institutions were investing in their own libraries, so I argue that collaboration should not take the place of local investment in equipment and human resources. While not every library will have the resources to create its own digitization lab or hire digitization specialists, every library does have the capacity to gain knowledge of digitization and preservation best practices on staff. Catalogers can learn new metadata formats for the digital age. Staff can learn grant-writing skills. Overall, the push toward the digital should be seen as motivation to update our skill sets as library staff, and it makes imperative the need to argue with administration for growing and shifting local budgets to grow digitization capacity. We should use the Association as a gateway to doing that, but we should not overlook the importance of maintaining capacity at the local level, which benefits us all.

It is rather obvious to state that digital collections are an important part of our libraries' future. I believe that by working together, in the spirit of the microfilming project of years ago, we can have great success in ensuring continued access to the rare treasures of our local libraries.

\section{INFORMATION LITERACY}

I close with what I believe may be the biggest challenge, and therefore the greatest opportunity, of our post-pandemic digital world: information literacy. As I noted in my historical review, the earliest collaborative project in the Association was the creation of an index to periodical literature, an attempt to help librarians, and in turn their patrons, navigate the world of theological literature in a period of its tremendous growth. I shudder to think what those respondents to the ALA survey in 1937-those who complained about the inability to find quality resources in theology and religious studies-would say about the information environment that librarians are asked to navigate. There has been an exponential explosion in information available, since the advent of the internet of course, but increasingly 
with the growth of open-access journals, self-publishing, and scholarship on social media. My prayers are with the librarians who have to help patrons sift through the millions of results returned from their initial Google search on topics like "Augustine" or "Eucharist" or "preaching." No index of literature, no matter how systematic and far-reaching, could possibly be comprehensive, and even if it did exist, it is unlikely that patrons are going to turn to it before they turn to their habituated Google search.

The pandemic, or at least events coinciding with the pandemic, have only made this more challenging, with the whittling of trust in traditional authorities, the destruction of the illusion of the objective, disinterested reporter or scholar, and the rise of misinformation. If we are operating in a post-truth world, how are we to instruct our patrons? What role can librarians play in leading patrons to reliable information in theology and religious studies?

As I noted, I affirm that this is our greatest challenge, the one that most demands our rethinking of our traditional practices, and the one most in need of that attack from Atla librarians. I am not so bold as to suggest I have a singular answer to it, but I see ways forward that may be most helpful. Again, I return to Stuehrenberg's four principles as a way of exploring what that way forward may be.

First, efforts to teach information literacy should "involve as many members as possible." Collaboration across the Association feels a bit strange when we talk about reference and instruction, but cross-library collaboration is essential. To date, collaboration in this area has primarily focused on the production of reference materials that local librarians could use in their instruction, materials like the index of periodical literature. But the digital age opens up opportunities to shift this model to incorporate instruction itself. One of the great successes of the pandemic has been libraries moving to virtual instruction. In my own context at Pitts Theology Library, our reference team, led by Brady Beard and Anne Marie McLean, took their entire schedule of in-person workshops, converted them to livestream events, and then edited them for YouTube. ${ }^{1}$ Not only is the content now available for all, but using our BigMarker webinar system, they schedule watch parties for this recorded content, where they are available live to chat and answer questions as patrons watch 
the recording. ${ }^{2}$ What this suggests is that the brilliant content that each library is generating in its own local context can be shared and made available, so that patrons now not only have access to their local reference librarian, but to content generated by reference librarians around the world.

With this technology in place, I would argue that we need to work together to avoid duplicating content, and rather rely on one another to provide localized content globally. Why, for example, should we all run the same workshop on using Zotero, when we can coordinate the creation of digital content, and then watch it locally alongside our patrons and answer their questions as they arise?

Second, in addition to collaborating on new content, we should "leverage existing resources." Many libraries have on staff reference librarians who, while they excel at the art of being a generalist (so essential to the role of the reference librarian), also have strong subject matter expertise. Members should work together to catalog and advertise such local expertise for the benefit of the association. The same is true for the content our librarians create. If there are LibGuides that a library's patron base finds particularly helpful, how can that library advertise that availability for other libraries and other sets of patrons?

This sharing of resources is particularly important as the breadth of content for instruction in "theology" has so expanded. Many librarians are not only being asked to teach patrons how to do research in theology and religious studies, but also how to take advantage of new technologies like text mining, geospatial mapping, and big data curation, as research in all areas, even religion, increasingly incorporates new skills. Our expectation should not be that each librarian become a master of all of these trades. We do, however, have colleagues who can help. In my library, for example, we are fortunate to have on staff a digital scholarship librarian, Spencer Roberts, who has wide-ranging technical expertise. We should work as an Association to catalog and communicate such capacities on our staff, with the hopes of using digital technology to leverage these existing resources to support our patrons.

Third, when collaborating, we should "allow decentralized decision-making." As noted before, a push to centralize and collaborate should not get in the way of local decisions. With reference and

2 See https://www.bigmarker.com/communities/pitts-theology-library/ conferences. 
instruction, our local patrons must come first, and so if there are needs at the local level, we should adjust our reference practices to meet those. For a Methodist institution, for example, local knowledge of the conferences in the UMC is not something that should be farmed out to the Association. As with collections, we must identify what it is our local patrons need and align our local expertise with those needs.

Finally, librarians must "know when enough is enough.” Libraries must not only shift the mode of instruction toward a more collaborative one, but the information explosion of the digital age demands new skills amongst our librarians, and collaborative efforts in instruction should not get in the way of cultivating those skills locally. The demands of our patrons, particularly student patrons, who are stumbling their way to learning in a world of Wikipedia, Google, and Twitter, are best met with local instruction, and I must admit, in-person instruction. So, just as Raymond Morris was concerned that the Library Development Program could have the unintended consequence of creating a dependency that was not sustainable, so we must be aware that centralized and collaborative instruction has the potential of whittling down our local expertise and keeping us from reaching our patrons. Let us keep that from happening by collaborating on the content we can collaborate on, but focusing also on our local patrons. Indeed, done properly, the shared content of instruction I have mentioned before should free up the time and capacity of our reference librarians to help our students. Increasingly, if we can rely on the Association to help with content, such as identifying basic resources for Methodist Studies, then local librarians can teach our patrons how to read, assess, and critique those basic resources. Critical information literacy is essential in this world of too much to know, and I believe this is the area our librarians should focus on.

\section{CONCLUSION}

I have outlined three areas-collection development, access/preservation, and information literacy-where theological librarians have collaborated before, and where they should collaborate again, but with a strategic vision. I hope I have outlined some of the challenges we face well enough to convince you that a strong association is exactly what we need.

What I have not offered, of course, is a set of specific directives about how to do this. I leave that to those who are far more creative 
than I to find specific solutions. I will say, though, that these solutions are likely found within this Association, by working together. Our infrastructure is there. The Atla Interest Groups are doing incredible work in many of the areas discussed. Perhaps we need more or an updated set. The Atla association itself is providing us with resources to collaborate, from the Atla Digital Library, to grant support, to in-house expertise in areas like digital resources, scholarly communications, and metadata. As we rise to meet many of these challenges in a post-pandemic digital age, I encourage us to rely on Atla and our membership to meet them together.

I return to where I started, the name of our shared association. Now more than ever, we need an association. Certainly, we need it as a way of professionalization. But in these challenging times, it is through collaboration that we will not only survive, but thrive. To finish out the branding exercise, I have in this process discovered new appreciation for the "subtitle" as it were in the new brand: "Collectors and Connectors in Religion and Theology." While I have typically been thinking of that second term, "Connectors," to mean that we, as librarians, are the key to connect our patrons to the resources they need, I hope you can join me in seeing that Atla plays a role in connecting us librarians to one another, to explore how we can work together to meet the significant challenges we face.

\section{REFERENCE LIST}

Banks, Joy and Christa Williford. 2018. "Collaborative Grants: Why Do We Care?” CLIR Issues 126 (November). https://www.clir. org/2018/12/clir-issues-126.

Bartholomew, Jennifer. 2019. "The Next Chapter: Realizing the Atla Vision.” Accessed June 1, 2021. https://www.atla.com/blog/thenext-chapter-realizing-the-atla-vision/

Chace, Myron B. 1996. "ATLA’s Preservation Microfilming Program: Growing Out of Our Work.” In The American Theological Library Association: Essays in Celebration of the First Fifty Years, edited by M. Patrick Graham, Valerie R. Hotchkiss, and Kenneth E. Rowe, 47-59. Evanston, IL: The American Theological Library Association.

Devezin, Latoya. 2017. "Building Bridges: Creating Collaborative Partnerships Between Large and Small Institutions,” CLIR Blog, 
February 16, 2017. https://rethinking.clir.org/blog/buildingbridges-creating-collaborative-partnerships-between-large-andsmall-institutions/.

Dickerson, G. Fay and John A. Pelz. 2006. "The Index to Religious Periodical Literature: Past, Present, and Future.” In A Broadening Conversation: Classic Readings in Theological Librarianship, edited by Melody Layton McMahon, 298-305. Lanham, MD: Scarecrow Press.

Graham, M. Patrick, Valerie R. Hotchkiss, and Kenneth E. Rowe, editors. 1996. The American Theological Library Association: Essays in Celebration of the First Fifty Years. Evanston, IL: The American Theological Library Association.

May, Mark A. 1934. The Institutions that Train Ministers. The Education of American Ministers, volume 3. New York: Institute of Social and Religious Research.

McMahon, Melody Layton, editor. 2006. A Broadening Conversation: Classic Readings in Theological Librarianship. Lanham, MD: Scarecrow Press.

Morris, Sara E. and Jenny Presnell. 2019. “Collection Development and the Historical Record: Are We Forgetting Monographs as Primary Sources?" Collection Management 44, nos. 2-4: 379-388.

Nichols, Stephen G. and Abby Smith. 2001. The Evidence in Hand: Report of the Task Force on the Artifact in Library Collections. Washington, DC: Council on Library and Information Sources. O'Brien, Elmer J. and Betty A. 1996. "From Volunteerism to Corporate Professionalism: A Historical Sketch of the American Theological Library Association.” In The American Theological Library Association: Essays in Celebration of the First Fifty Years, edited by M. Patrick Graham, Valerie R. Hotchkiss, Kenneth E. Rowe, 3-24. Evanston, IL: The American Theological Library Association.

"Proposed Constitution: First Draft, 1947." In Conference of Theological Librarians Summary of Proceedings held at Louisville Presbyterian Seminary in Louisville, KY, June 23-24, 1947, by the Conference of Theological Librarians, 75. Chicago: Conference of Theological Librarians. 
Stuehrenberg, Paul F. 1996. "A Giant Step Forward: The Sealantic Fund and the American Theological Library Association Library Development Project.” In The American Theological Library Association: Essays in Celebration of the First Fifty Years, edited by M. Patrick Graham, Valerie R. Hotchkiss, and Kenneth E. Rowe, 60-72. Evanston, IL: The American Theological Library Association. 